\title{
Spectroscopy blog challenge
}

\section{Journal Article}

\section{Author(s):}

Pretsch, Ernö; Zenobi, Renato

\section{Publication date:}

2008

\section{Permanent link:}

https://doi.org/10.3929/ethz-b-000014117

\section{Rights / license:}

In Copyright - Non-Commercial Use Permitted

\section{Originally published in:}

Analytical and Bioanalytical Chemistry 392(1-2), https://doi.org/10.1007/s00216-008-2267-6 


\section{Spectroscopy blog challenge}

\author{
E. Pretsch $\cdot$ R. Zenobi \\ Published online: 2 August 2008 \\ (C) Springer-Verlag 2008
}

We would like to invite you to participate in a new 'Analytical Challenge' format: The 'Spectroscopy blog challenge'. Over the past 5 years the 'Analytical Challenge' has established itself as a truly unique quiz series, with a new scientific puzzle published every other month, but this time all readers are invited to solve the puzzle jointly, in blog discussions.

Please register at http://blogs.springer.com/abc and participate by sharing your ideas and responding to other participants' contributions. The authors of this Challenge, E. Pretsch and R. Zenobi, will also join the discussions and help by providing a hint should the trail of discussion lead astray.

And please note that there is a prize to be won (a Springer book of your choice up to a value of $€ 75$ ). The winner will be determined based on an evaluation of the relevance of his/her input to solving the 'Challenge'. In the present challenge spectroscopy is the topic. Please read on...

\section{Meet the first spectroscopy blog challenge}

The challenge

The present challenge in spectra interpretation is an unusually hard one, but it can be solved almost completely with the available spectroscopic information. The idea of the online blog in this case is that individuals interested in solving the puzzle can help each other by passing on hints and asking questions. The authors will also participate in this online forum from time to time. Furthermore, we might release more spectroscopic information that is necessary to

\footnotetext{
E. Pretsch

ETH Zürich,

8092 Zürich, Switzerland

e-mail: pretsche@ethz.ch

R. Zenobi $(\bowtie)$

ETH Zürich,

8093 Zürich, Switzerland

e-mail: zenobi@org.chem.ethz.ch
}

arrive at the correct structure of the unknown molecule, and if necessary respond to concrete questions from participants in the blog.

The pieces of information necessary for solving the challenge are the following:

Mass spectrometry:

- tentative assignment of molecular mass

- occurrence of elements from nominal mass and isotope distribution

- type of compound from ion series and intensity distribution

- structural elements form neutral losses (mass differences of the first fragments relative to the molecular ion)

Infrared spectroscopy:

- identification of functional groups from typical absorbances $(\mathrm{OH}, \mathrm{NH}$, special types of $\mathrm{CH}$, groups with triple bonds and cumulated double bonds, $\mathrm{C}=\mathrm{O}, \mathrm{C}=\mathrm{C}$, aromatics). Except for the most simple cases, only very intensive signals should be interpreted in the fingerprint region $\left(1,500-1,000 \mathrm{~cm}^{-1}\right)$ at this stage.

Proton NMR spectroscopy:

- integrated intensities, possible total numbers of protons

- chemical environment of protons from the chemical shifts

- neighboring groups from first-order splittings

- symmetrical second-order spin systems

Carbon-13 NMR spectroscopy:

- number of signals: possible minimal number of carbon atoms

- number of protons attached to carbon atoms

- equivalent carbons from comparison with the integrals in the proton NMR spectrum and the presence of $\mathrm{X}-\mathrm{H}$ $(X \neq C)$ groups from the IR spectrum

- chemical environment of carbons from the chemical shifts

2D NMR spectra (e.g., DEPT, HSQC, and H,H-COSY):

- determination of spin multiplicity of ${ }^{13} \mathrm{C}$ NMR signals

- clarification of connectivity in complicated spin systems

- distinction of short-range and long-range couplings 
We invite our readers to participate in the Analytical Challenge by solving the puzzle above by October 20, 2008, jointly in blog discussions. Please go to http://blogs. springer.com/abc and log in, click on the title 'Spectroscopy blog challenge' to read comments and add your reply to participate in this blog challenge. The winner will be notified by e-mail and his/her name will be published on the 'Analytical and Bioanalytical Chemistry' website at http://www.springer.com/abc and in the journal. Readers will find the solution and a short explanation on the 'Analytical and Bioanalytical Chemistry' website after October 20, 2008, and in the journal (Issue 393/1).

If you have enjoyed solving this Challenge you are invited to try the previous puzzles on the 'Analytical and Bioanalytical Chemistry' website. The next Analytical Challenge will be published in Issue 392/5, November 2008.

\section{IR: $\quad$ Perkin-Elmer Model FT-IR 1600 recorded $\mathrm{CHCl}_{3}$}

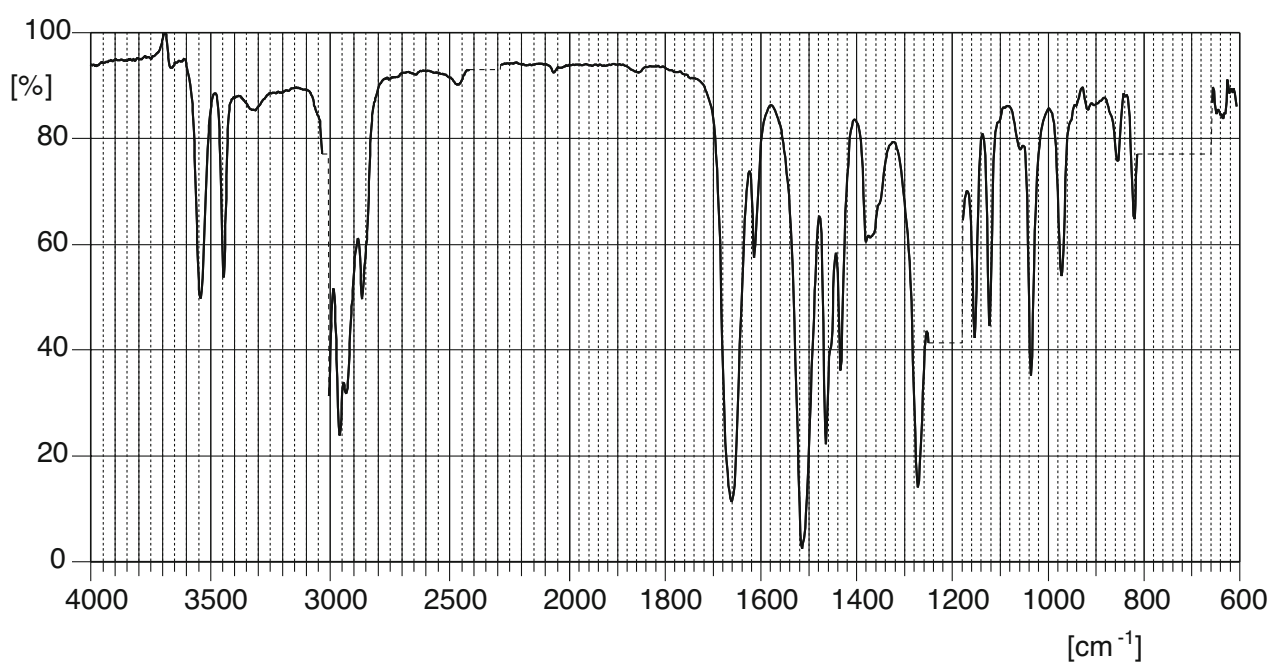

MS:

El, $70 \mathrm{eV}$

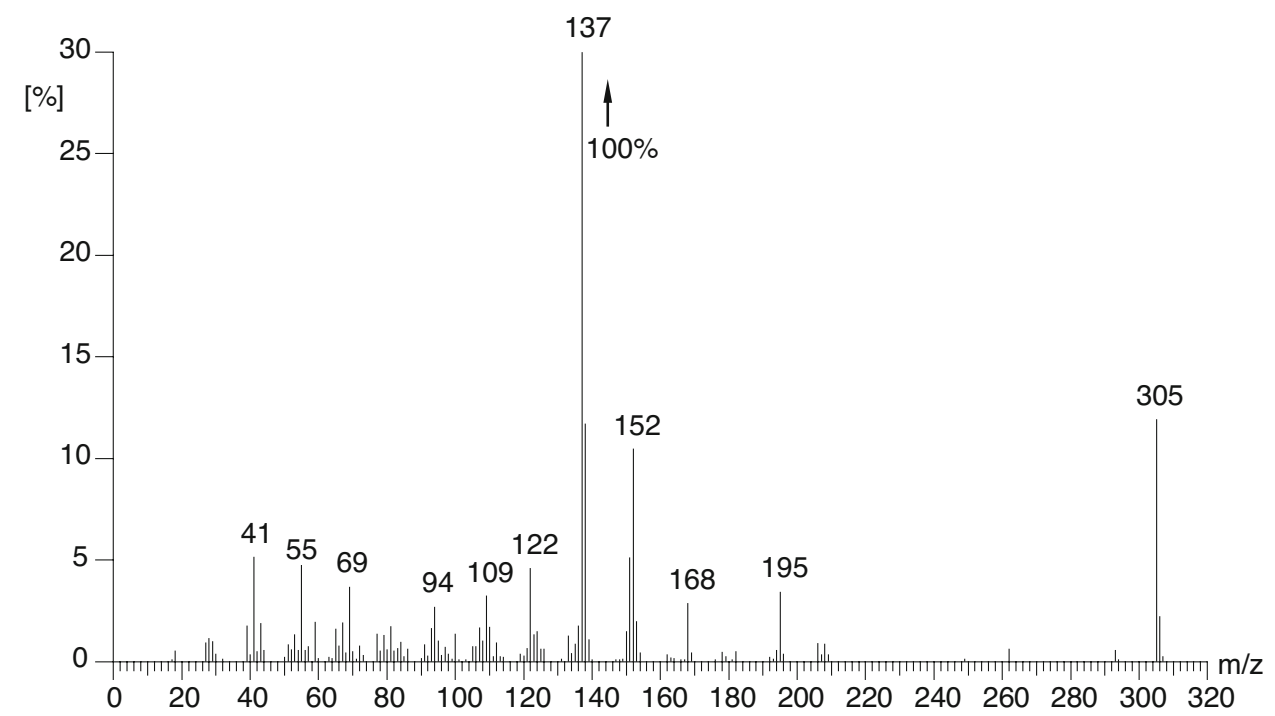


${ }^{13} \mathrm{C}-\mathrm{NMR}: 50 \mathrm{MHz}$, recorded $\mathrm{CDCl}_{3}$ above: ${ }^{1 H}$ decoupled below: DEPT
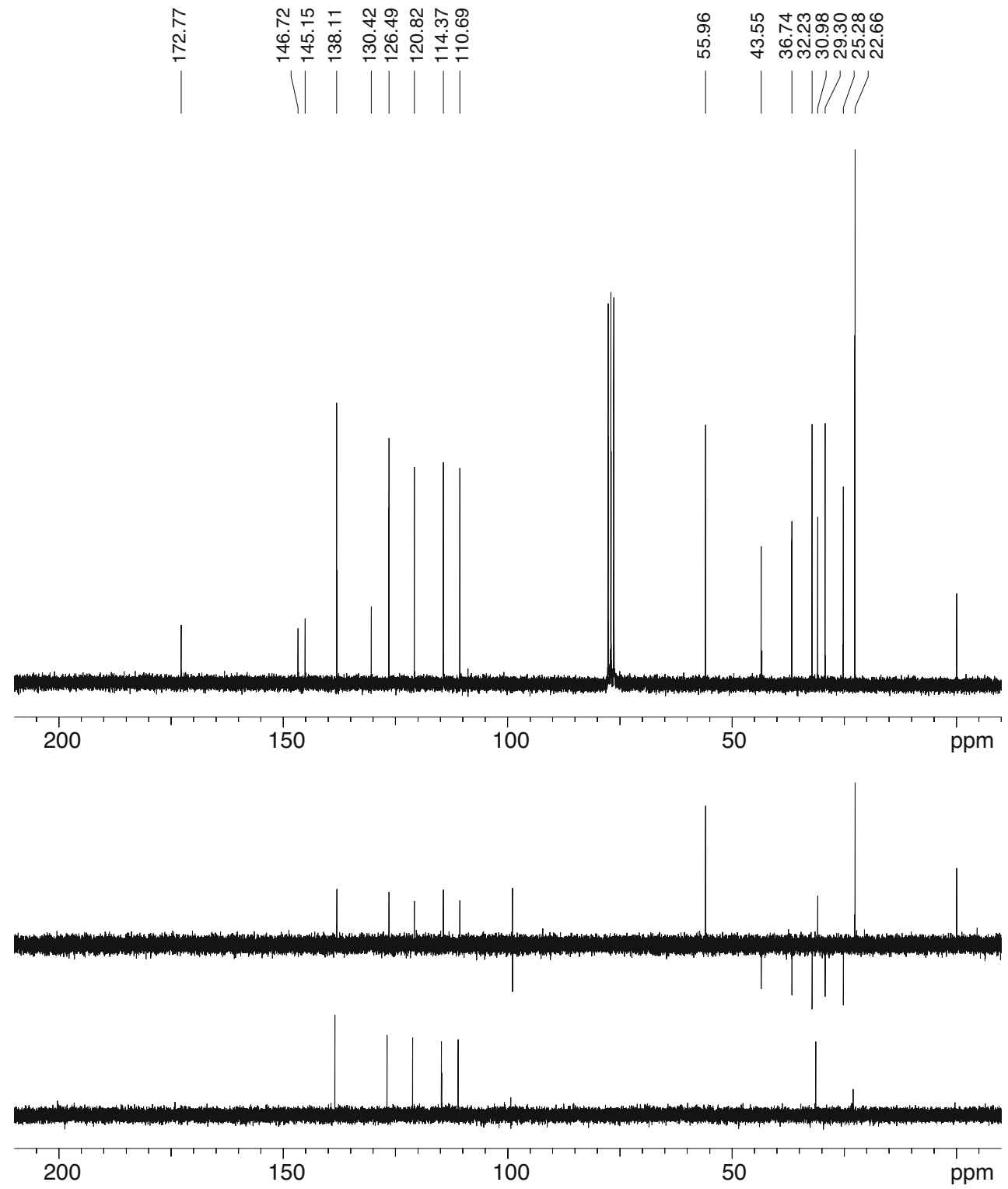
${ }^{1} \mathbf{H}$-NMR: $400 \mathrm{MHz}$, recorded in $\mathrm{CDCl}_{3}$
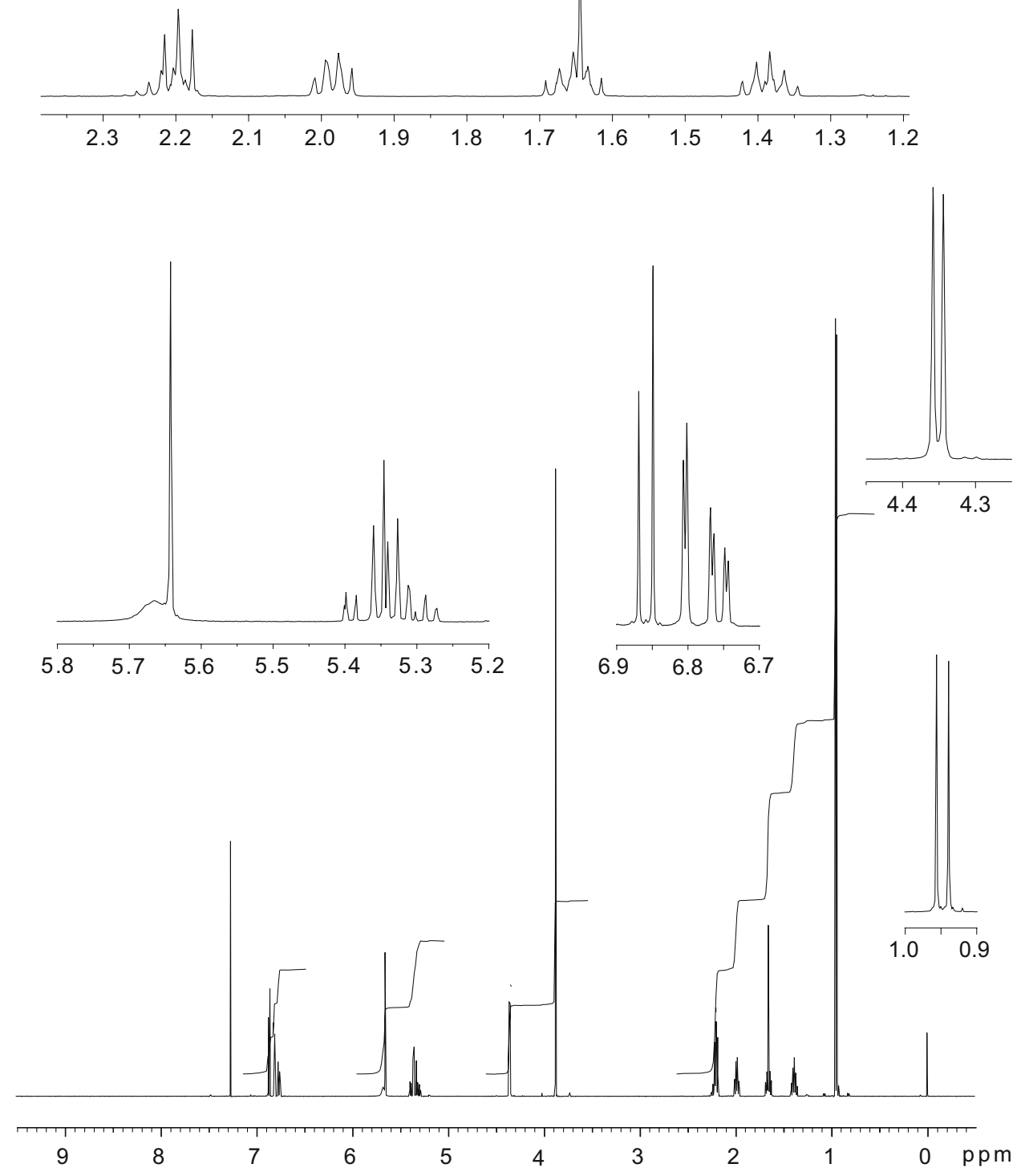
HSQC: recorded in $\mathrm{CDCl}_{3}$

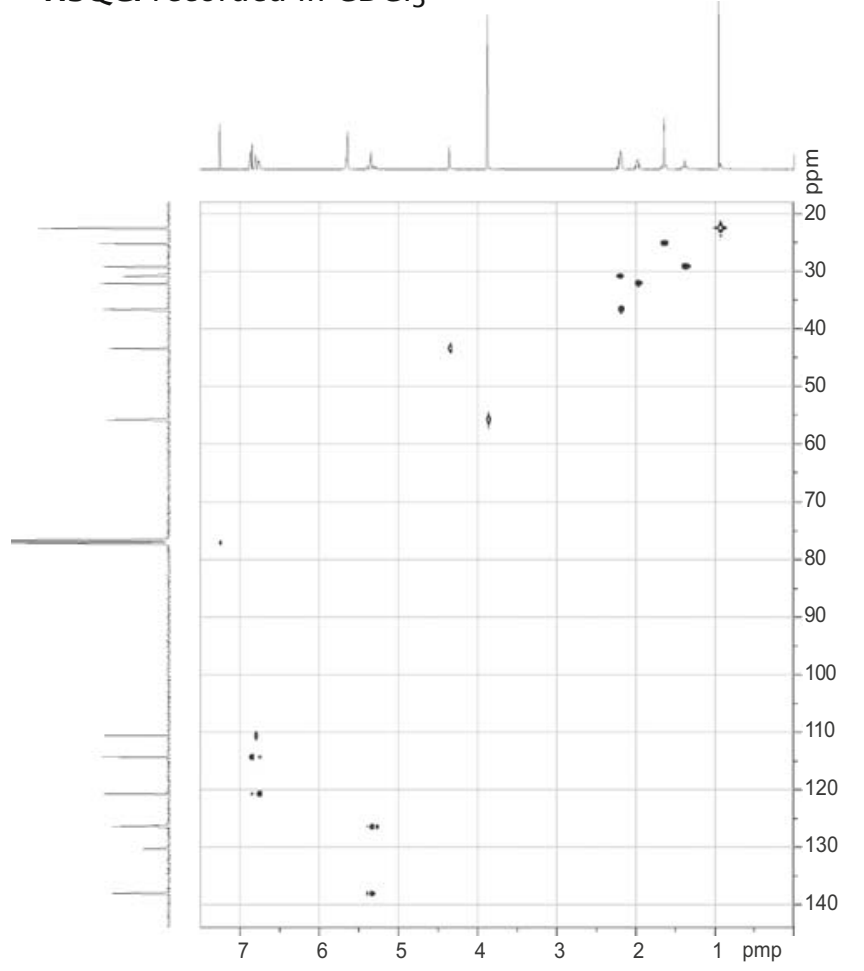

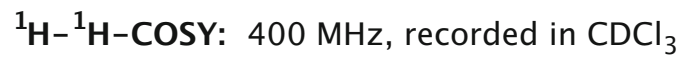

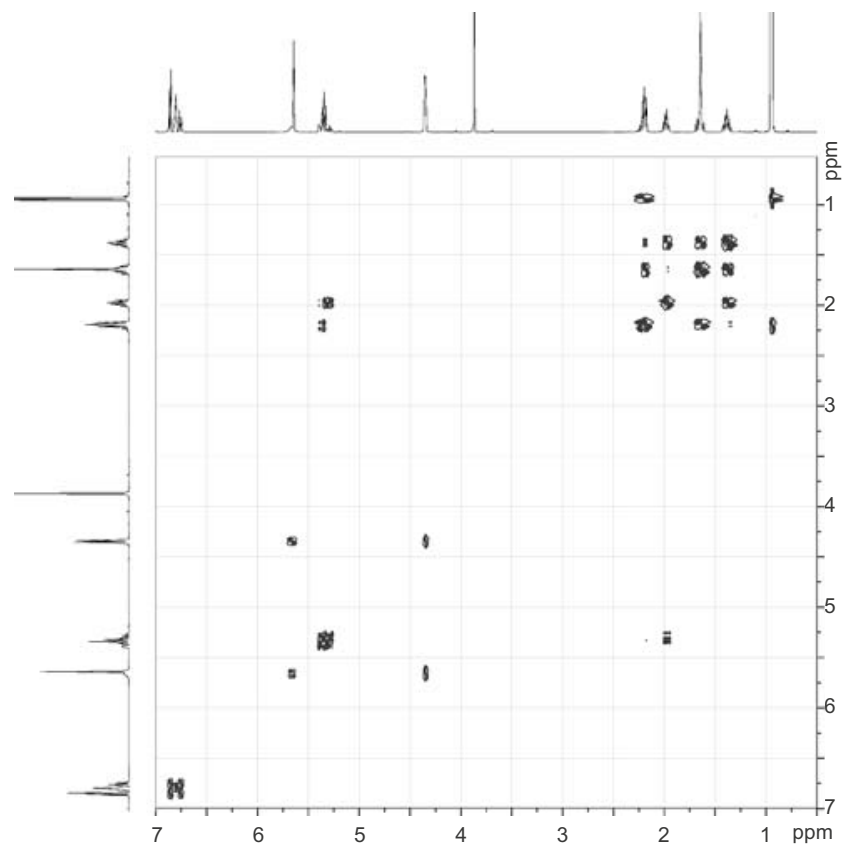

